\title{
Human Papillomavirus-16 Positive
}

National Cancer Institute

\section{Source}

National Cancer Institute. Human Papillomavirus-16 Positive. NCI Thesaurus. Code C129455.

Indicates that human papillomavirus-16 has been detected in a sample. 